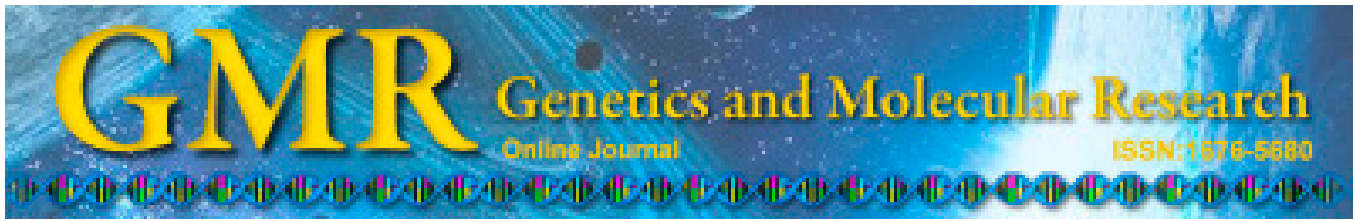

\title{
Vitamin D receptor FokI gene polymorphism and tuberculosis susceptibility: a meta-analysis
}

\author{
Y.P. Sun and Q.S. Cai \\ Corresponding author: Q.S. Cai \\ E-mail: caiqsmed@126.com \\ Genet. Mol. Res. 14 (2): 6156-6163 (2015) \\ Received August 5, 2014 \\ Accepted January 19, 2015 \\ Published June 9, 2015 \\ DOI http://dx.doi.org/10.4238/2015.June.9.1
}

Department of Tuberculosis, Hangzhou Red Cross Hospital, Hangzhou, China

\begin{abstract}
Numerous studies have evaluated the association between FokI polymorphisms in the vitamin D receptor (VDR) gene and tuberculosis risk. However, the specific association remains controversial. In this study, we performed a meta-analysis to assess the association between the $V D R$ gene FokI polymorphism and tuberculosis. Published studies from the PubMed and Embase databases were retrieved. The pooled odds ratio $(\mathrm{OR})$ with $95 \%$ confidence interval $(\mathrm{CI})$ was calculated using fixed- or random-effect models. Overall, a significant association was found between FokI polymorphism and tuberculosis risk when all studies were pooled (ff $v s \mathrm{FF}$ : $\mathrm{OR}=1.36,95 \% \mathrm{CI}=1.11-1.66$; ff $v s \mathrm{Ff}$ : OR $=1.38,95 \% \mathrm{CI}=1.14-1.67$; dominant model: $\mathrm{OR}=0.73,95 \% \mathrm{CI}=0.61-$ 0.88 ). In subgroup analysis by race, a significant association between FokI polymorphism and tuberculosis risk was observed in Asians (ff $v s$ FF: $\mathrm{OR}=1.71,95 \% \mathrm{CI}=1.02-2.85$; ff $v s$ Ff: $\mathrm{OR}=1.86,95 \% \mathrm{CI}=1.40-$ 2.47; dominant model: $\mathrm{OR}=0.55,95 \% \mathrm{CI}=0.42-0.72$ ), and no significant association was observed among Caucasians and Africans. In conclusion, the FokI polymorphism in the $V D R$ gene may be related to an increased risk of tuberculosis in Asians. Further large and well-designed studies are needed to confirm these conclusions.
\end{abstract}

Key words: FokI polymorphism; Tuberculosis; Vitamin D receptor 


\section{INTRODUCTION}

Tuberculosis is an infectious disease and remains a major public health concern as well as leading cause of morbidity and mortality worldwide (Zembrzuski et al., 2010). According to a report from the World Health Organization, there were an estimated 8.6 million cases of tuberculosis and 1.3 million deaths in 2012 (Zumla et al., 2013). Despite numerous studies, the causes are not fully understood. In addition to well-established risk factors (such as human immunodeficiency virus, malnutrition, and young age), emerging variables such as diabetes, indoor air pollution, alcohol, use of immunosuppressive drugs, and tobacco smoke are recognized risk factors that are confounded by socioeconomic status (Davies, 2005). In addition, genetic factors play an important role in tuberculosis development (Thye et al., 2010).

Recent studies have shown that vitamin D deficiency is associated with skeletal abnormalities, including muscle weakness, bone pain, and fragility fractures (Holick, 2007). Non-skeletal effects of vitamin D deficiency, including diabetes and immune dysfunction, have also been reported (Pittas et al., 2007; Hewison, 2008). Moreover, vitamin D modulates monocyte and macrophage activity in the body and plays a role in human innate immunity to certain infectious agents, including tuberculosis (Haussler et al., 1998). A meta-analysis recently showed that low serum vitamin $\mathrm{D}$ levels were associated with higher risk of active tuberculosis (Nnoaham and Clarke, 2008).

The effects of vitamin D are exerted through the vitamin D receptor (VDR), which is a member of the nuclear receptor family of transcription factors (Moore et al., 2006). The VDR gene, which is located on chromosome $12 \mathrm{cen}-\mathrm{q} 12$, contains 11 exons and spans approximately $75 \mathrm{~kb}$ of genomic DNA (Taymans et al., 1999). VDR gene FokI polymorphisms (rs10735810/ rs2228570) were reported to be in linkage disequilibrium with other $V D R$ polymorphisms. A change in the sequence from $\mathrm{f}$ to $\mathrm{F}$ in the start codon translation site leads to the generation of a polymorphic variant (FF) that is shortened by 3 amino acids and exhibits increased transcriptional efficiency of the VDR protein as compared to the long ff allele form (Uitterlinden et al., 2004).

To date, several studies have shown that the VDR gene FokI polymorphism is associated with tuberculosis. However, this specific association remains controversial. Metaanalysis is useful for detecting associations that could otherwise remain masked in the sample size studies, particularly in those evaluating rare allele frequency polymorphisms (Attia et al., 2003). The aim of this meta-analysis was to investigate the association between VDR gene FokI polymorphisms and tuberculosis risk by conducting a meta-analysis that included all eligible case-control studies published.

\section{MATERIAL AND METHODS}

\section{Literature search}

We performed an electronic search of the PubMed and Embase databases to retrieve papers examining the association between $V D R$ gene FokI polymorphism and susceptibility to tuberculosis available until July 2014 without language restrictions, using the following search terms: "vitamin D receptor/VDR", "Fokl", "rs10735810", "rs2228570", "tuberculosis", "polymorphism", "single-nucleotide polymorphism", and "genetic polymorphism". The reference lists of major textbooks, reviews, and included articles were manually searched 
to identify potentially eligible studies. Studies reported by the same authors, although published in different journals, were checked for possible overlapping participant groups. When pertinent data were not included, or data that were presented were unclear, the authors were contacted directly.

\section{Inclusion and exclusion criteria}

To minimize heterogeneity and facilitate the proper interpretation of this study, published articles included in the current meta-analysis had to meet all of the following criteria: i) case-control studies that included tuberculosis cases and healthy controls; ii) studies that evaluated the association between $V D R$ gene polymorphisms and tuberculosis risk; and iii) studies that included sufficient genotype data for extraction. Studies were excluded when: i) they were not case-control studies that evaluated the association between $V D R$ gene polymorphisms and tuberculosis risk; ii) they were case reports, letters, reviews, meta-analysis, or editorial articles; iii) they were studies that were based on incomplete raw data and those with no usable data reported; iv) the studies duplicate data; and v) a family-based design was used.

\section{Data extraction}

For each retrieved publication, the methodological quality assessment and data extraction were independently abstracted in duplicate by 2 independent investigators using a standard procedure. A data collection form was used to confirm the accuracy of the collected data by strictly following the inclusion criteria as stated above. The necessary data were as follows: first author, year of publication, country, nationality, number of patients and controls, polymorphisms of gene, and evidence of Hardy-Weinberg equilibrium (HWE) in controls. The accuracy of the retrieved data was examined by a senior reviewer.

\section{Statistical analysis}

All statistical analyses were performed using the STATA software (version 12.0, StataCorp., College Station, TX, USA). The contrast models involving the homozygous (ff $v_{s} \mathrm{FF}$ ), additive (ff $\left.v s \mathrm{Ff}\right)$, dominant $(\mathrm{FF}+\mathrm{Ff} v s \mathrm{ff})$, and recessive (ff $\left.+\mathrm{Ff} v s \mathrm{FF}\right)$ models were used. The pooled odds ratios (ORs) with the corresponding $95 \%$ confidence intervals (95\%CIs) were applied to estimate the strength of the association between the VDR gene FokI polymorphism and tuberculosis risk. We quantified the effect of heterogeneity using the $\mathrm{I}^{2}$ test. $\mathrm{I}^{2}$ ranges between 0 and $100 \%$ and represents the proportion of inter-study variability that can be attributed to heterogeneity rather than to chance. $I^{2}$ values of 25,50 , and $75 \%$ were defined as low, moderate, and high estimates, respectively. When $\mathrm{I}^{2}>50 \%$, heterogeneity was indicated across studies and the random-effect model was used for meta-analysis; otherwise, the fixed-effect model was used (Zhou et al., 2011; Zhong et al., 2012). Stratified analysis was performed according to ethnicity. For one study performed in America, the result of subgroup analysis by ethnicity could not be reliable (Roth et al., 2004). To assess the reliability of the outcomes in the meta-analysis, sensitivity analysis was performed to exclude studies whose allele frequencies in controls exhibited significant deviation from HWE. Funnel plot asymmetry was assessed by the Begg test to estimate potential publication bias and $\mathrm{P}<0.05$ was considered to indicate statistical significance. All P values were two-sided. 


\section{RESULTS}

\section{Study characteristics}

Base on the inclusion criteria, 18 case-control studies with full-text were included in this meta-analysis (Wilkinson et al., 2000; Bornman et al., 2004; Liu et al., 2004; Roth et al., 2004; Lombard et al., 2006; Babb et al., 2007; Olesen et al., 2007; Soborg et al., 2007; Alagarasu et al., 2009; Merza et al., 2009; Selvaraj et al., 2003, 2004, 2009; Zhang et al., 2010; Ates et al., 2011; Singh et al., 2011; Rathored et al., 2012; Joshi et al., 2014). These 18 case-control studies included a total of 3160 tuberculosis cases and 3619 healthy controls. The year of publication of the included studies ranged from 2000 to 2014. All articles were written in English. There were 10 studies in Asians, 4 studies in Africans, 3 studies in Europeans, and 1 study in Americans. The HWE test was performed to examine the genotype distribution of the controls, and all were in HWE except the study population in the study by Merza et al. (2009). The baseline characteristics and methodological quality of all studies included are summarized in Table 1.

\begin{tabular}{|c|c|c|c|c|c|c|c|c|c|c|}
\hline \multirow[t]{2}{*}{ Study included } & \multirow[t]{2}{*}{ Area } & \multirow[t]{2}{*}{ Race } & \multirow[t]{2}{*}{ Cases/Controls } & \multicolumn{3}{|c|}{ Genotypes for cases } & \multicolumn{3}{|c|}{ Genotypes for controls } & \multirow[t]{2}{*}{ HWE test } \\
\hline & & & & $\mathrm{FF}$ & $\mathrm{Ff}$ & $\mathrm{ff}$ & $\mathrm{FF}$ & Ff & $\overline{\mathrm{ff}}$ & \\
\hline Wilkinson et al. (2000) & England & Caucasians & $91 / 116$ & 52 & 31 & 8 & 74 & 39 & 3 & 0.42 \\
\hline Selvaraj et al. (2003) & India & Asians & $120 / 80$ & 78 & 36 & 6 & 43 & 29 & 8 & 0.36 \\
\hline Bornman et al. (2004) & South Africa & Africans & $417 / 722$ & 258 & 138 & 20 & 444 & 242 & 32 & 0.89 \\
\hline Liu et al. (2004) & China & Asians & $120 / 240$ & 29 & 63 & 28 & 85 & 120 & 35 & 0.48 \\
\hline Roth et al. (2004) & Peru & Americans & $103 / 206$ & 9 & 32 & 59 & 14 & 78 & 109 & 0.99 \\
\hline Selvaraj et al. (2004) & India & Asians & $46 / 64$ & 28 & 15 & 3 & 38 & 23 & 3 & 0.84 \\
\hline Lombard et al. (2006) & South Africa & Africans & $66 / 86$ & 43 & 21 & 2 & 66 & 18 & 2 & 0.57 \\
\hline Babb et al. (2007) & South Africa & Africans & $249 / 352$ & 132 & 104 & 13 & 203 & 129 & 20 & 0.93 \\
\hline Olesen et al. (2007) & Gambia & Africans & $320 / 344$ & 198 & 106 & 16 & 207 & 118 & 19 & 0.69 \\
\hline Soborg et al. (2007) & Denmark & Caucasians & $435 / 416$ & 288 & 128 & 19 & 267 & 128 & 21 & 0.27 \\
\hline Alagarasu et al. (2009) & India & Asians & $224 / 146$ & 138 & 66 & 13 & 81 & 59 & 4 & 0.08 \\
\hline Merza et al. (2009) & Iran & Asians & $117 / 60$ & 67 & 46 & 4 & 35 & 25 & 0 & 0.04 \\
\hline Selvaraj et al. (2009) & India & Asians & $65 / 60$ & 33 & 29 & 3 & 33 & 26 & 1 & 0.10 \\
\hline Zhang et al. (2010) & China & Asians & $110 / 102$ & 16 & 43 & 51 & 26 & 47 & 29 & 0.43 \\
\hline Ates et al. (2011) & Turkey & Caucasians & $128 / 80$ & 58 & 60 & 10 & 35 & 37 & 8 & 0.69 \\
\hline Singh et al. (2011) & India & Asians & $101 / 225$ & 55 & 40 & 6 & 96 & 110 & 19 & 0.11 \\
\hline Rathored et al. (2012) & India & Asians & $338 / 205$ & 175 & 115 & 48 & 118 & 80 & 7 & 0.14 \\
\hline Joshi et al. (2014) & India & Asians & $110 / 115$ & 51 & 46 & 13 & 63 & 41 & 11 & 0.27 \\
\hline
\end{tabular}

\section{Quantitative data synthesis}

A summary of the meta-analysis findings regarding the association between the VDR gene FokI polymorphism and tuberculosis risk is shown in Table 2 and Figure 1. We found a significant association between Fok I polymorphism and tuberculosis risk in all of the genetic models (ff $v s \mathrm{FF}: \mathrm{OR}=1.36,95 \% \mathrm{CI}=1.11-1.66$; ff $v_{s} \mathrm{Ff}: \mathrm{OR}=1.38,95 \% \mathrm{CI}=1.14-1.67$; dominant model: $\mathrm{OR}=0.73,95 \% \mathrm{CI}=0.61-0.88$; recessive model: $\mathrm{OR}=1.04,95 \% \mathrm{CI}=0.94-1.15$ ).

In subgroup analysis by ethnicity, there were significant associations between FokI polymorphism and tuberculosis risk in Asian populations (ff $v s \mathrm{FF}: \mathrm{OR}=1.71,95 \% \mathrm{CI}=1.02-2.85$; ff vs Ff: $\mathrm{OR}=1.86,95 \% \mathrm{CI}=1.40-2.47$; dominant model: $\mathrm{OR}=0.55,95 \% \mathrm{CI}=0.42-0.72$; recessive model: $\mathrm{OR}=1.06,95 \% \mathrm{CI}=0.82-1.37$ ). No significant association was found in Caucasians 
(ff $v s$ FF: $\mathrm{OR}=1.14,95 \% \mathrm{CI}=0.50-2.58$; ff $v s$ Ff: $\mathrm{OR}=1.06,95 \% \mathrm{CI}=0.64-1.77$; dominant model: $\mathrm{OR}=0.96,95 \% \mathrm{CI}=0.59-1.56$; recessive model: $\mathrm{OR}=0.98,95 \% \mathrm{CI}=0.78-1.23$ ) and in Africans (ff $v s \mathrm{FF}: \mathrm{OR}=1.01,95 \% \mathrm{CI}=1.69-1.46$; ff $v s \mathrm{Ff}: \mathrm{OR}=0.96,95 \% \mathrm{CI}=0.65-1.40$; dominant model: $\mathrm{OR}=1.01,95 \% \mathrm{CI}=0.70-1.46$; recessive model: $\mathrm{OR}=1.06,95 \% \mathrm{CI}=0.90$ 1.24). Furthermore, sensitivity analysis was performed with controls in HWE and the result was not altered, suggesting that the results of this meta-analysis were stable.

Table 2. Summary ORs and 95\%CI of vitamin D receptor FokI gene polymorphism and tuberculosis risk.

\begin{tabular}{|c|c|c|c|c|c|c|c|c|c|}
\hline \multirow[t]{2}{*}{ Subgroup } & \multirow[t]{2}{*}{ Genetic model } & \multirow{2}{*}{$\frac{\text { Sample size }}{\text { Case/Control }}$} & \multirow[t]{2}{*}{ Type of model } & \multicolumn{2}{|c|}{ Test of heterogeneity } & \multicolumn{2}{|c|}{ Test of association } & \multicolumn{2}{|c|}{ Test of publication bias } \\
\hline & & & & $\mathrm{I}^{2}$ & $\mathrm{P}$ & OR & $95 \% \mathrm{CI}$ & $\mathrm{z}$ & $\mathrm{P}$ \\
\hline \multirow[t]{4}{*}{ Overall } & $\mathrm{ff} v s \mathrm{FF}$ & \multirow[t]{4}{*}{$3160 / 3619$} & Fixed & $48.9 \%$ & 0.01 & 1.36 & $1.11-1.66$ & 0.00 & 1.00 \\
\hline & $\mathrm{ff} v s \mathrm{Ff}$ & & Fixed & $27.0 \%$ & 0.14 & 1.38 & $1.14-1.67$ & 0.00 & 1.00 \\
\hline & Dominant model & & Fixed & $40.5 \%$ & 0.04 & 0.73 & $0.61-0.88$ & 0.00 & 1.00 \\
\hline & Recessive model & & Fixed & $34.0 \%$ & 0.08 & 1.04 & $0.94-1.15$ & 0.00 & 1.00 \\
\hline \multirow[t]{4}{*}{ Caucasians } & $\mathrm{ff} v s \mathrm{FF}$ & \multirow[t]{4}{*}{$654 / 612$} & Random & $52.6 \%$ & 0.12 & 1.14 & $0.50-2.58$ & 0.00 & 1.00 \\
\hline & ff $v s \mathrm{Ff}$ & & Random & $36.8 \%$ & 0.21 & 1.06 & $0.64-1.77$ & 0.00 & 1.00 \\
\hline & Dominant model & & Fixed & $50.0 \%$ & 0.14 & 0.96 & $0.59-1.56$ & 0.00 & 1.00 \\
\hline & Recessive model & & Fixed & $0.0 \%$ & 0.51 & 0.98 & $0.78-1.23$ & 0.00 & 1.00 \\
\hline \multirow[t]{4}{*}{ Asians } & ff $v s \mathrm{FF}$ & \multirow[t]{4}{*}{$1454 / 1503$} & Random & $55.5 \%$ & 0.02 & 1.71 & $1.02-2.85$ & 0.00 & 1.00 \\
\hline & $\mathrm{ff} v s \mathrm{Ff}$ & & Fixed & $27.0 \%$ & 0.20 & 1.86 & $1.40-2.47$ & 0.00 & 1.00 \\
\hline & Dominant model & & Fixed & $46.7 \%$ & 0.05 & 0.55 & $0.42-0.72$ & 0.00 & 1.00 \\
\hline & Recessive model & & Random & $55.1 \%$ & 0.02 & 1.06 & $0.82-1.37$ & 0.00 & 1.00 \\
\hline \multirow[t]{4}{*}{ Africans } & $\mathrm{ff} v s \mathrm{FF}$ & \multirow[t]{4}{*}{$1052 / 1504$} & Fixed & $0.0 \%$ & 0.95 & 1.01 & $1.69-1.46$ & 0.00 & 1.00 \\
\hline & $\mathrm{ff} v s \mathrm{Ff}$ & & Fixed & $0.0 \%$ & 0.94 & 0.96 & $0.65-1.40$ & 0.00 & 1.00 \\
\hline & Dominant model & & Fixed & $0.0 \%$ & 0.96 & 1.01 & $0.70-1.46$ & 0.00 & 1.00 \\
\hline & Recessive model & & Fixed & $14.6 \%$ & 0.32 & 1.06 & $0.90-1.24$ & 0.00 & 1.00 \\
\hline \multirow{4}{*}{$\begin{array}{l}\text { Consistent } \\
\text { with HWE }\end{array}$} & $\mathrm{ff} v s \mathrm{FF}$ & \multirow[t]{4}{*}{$3043 / 3559$} & Random & $50.8 \%$ & 0.01 & 1.31 & $0.95-1.81$ & 0.00 & 1.00 \\
\hline & $\mathrm{ff} v_{s} \mathrm{Ff}$ & & Fixed & $29.0 \%$ & 0.13 & 1.37 & $1.13-1.66$ & 0.00 & 1.00 \\
\hline & Dominant model & & Fixed & $42.5 \%$ & 0.03 & 0.74 & $0.62-0.89$ & 0.00 & 1.00 \\
\hline & Recessive model & & Fixed & $34.0 \%$ & 0.08 & 1.04 & $0.94-1.15$ & 0.00 & 1.00 \\
\hline
\end{tabular}

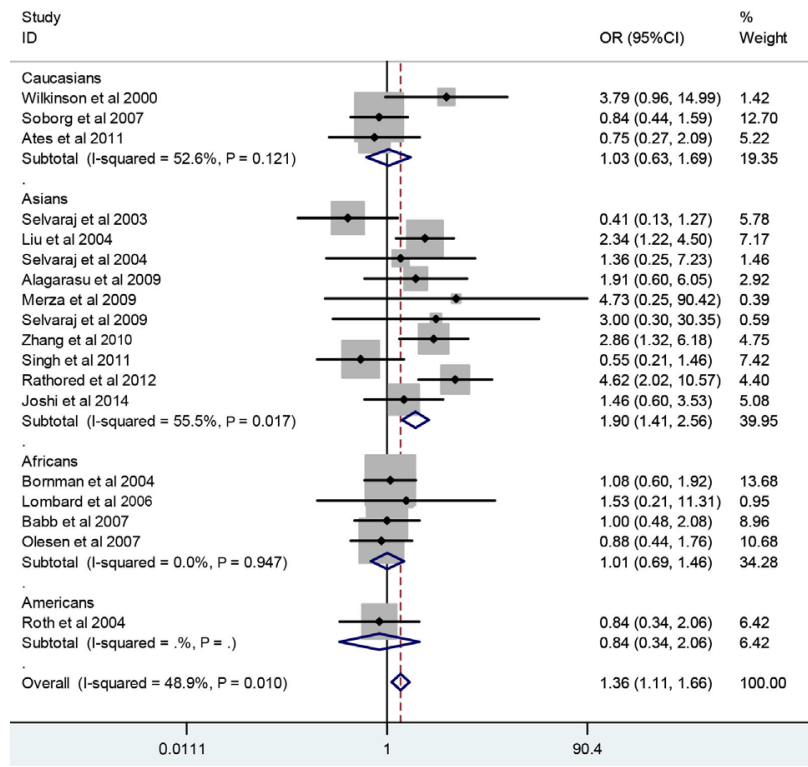

Figure 1. Meta-analysis for the association between tuberculosis risk and the VDR gene FokI polymorphism (ff vs FF) as illustrated in subgroup analysis. The STATA software could not calculate the data of Roth et al., 2004. 


\section{Publication bias}

Begg's funnel plot was used to assess publication bias in the reports included in the meta-analysis. The shape of funnel plots did not show evidence of publication bias. Publication bias was low in the present meta-analysis (all $\mathrm{P}>0.05$ ). Information concerning the Begg's funnel plot is shown in Table 2.

\section{DISCUSSION}

Vitamin D is known to have numerous functions in response to infection and is involved in the innate and acquired immune systems. These functions are related to the antimicrobial response to tuberculosis. The effects of vitamin D are exerted through VDR. Polymorphisms in the VDR gene may influence VDR activity and subsequent downstream vitamin D-mediated effects (Valdivielso and Fernandez, 2006). Numerous studies have revealed an association between $V D R$ gene FokI polymorphism and tuberculosis. However, the results have been inconsistent. Our meta-analysis quantitatively assessed the association between FokI polymorphism and tuberculosis risk for all eligible case-control studies published. A total of 18 case-control studies were included and assessed, which included a total of 3160 tuberculosis patients and 3619 healthy controls. The primary meta-analysis results showed that there were significant associations between FokI polymorphism and tuberculosis risk.

Because of differences in genetic backgrounds and the environment in the subjects, we performed ethnicity-specific subgroup analysis and found a significant association between FokI polymorphism and tuberculosis risk in Asians, but not in Caucasians and Africans. There are several reasons for the inconsistent results. First, tuberculosis is a complex multifactorial and multistage process. Several environmental factors, including dietary habits and intensity and hours of sunlight, influence $V D R$ gene expression in different populations. Previous studies suggested that Asian races were more susceptible to tuberculosis than were black and white races (Stead et al., 1990). Second, the FokI polymorphism site varied in different ethnicities. The f allele of the FokI polymorphism is less frequent in Africans compared to Asians (Uitterlinden et al., 2004). Thus, the current finding of this meta-analysis may be attributed to racial differences.

HWE is essential for a reliable case-control study. It is probable that studies that were not in HWE in controls resulted in selection bias or genotyping error, making the results misleading. Sensitivity analysis was performed by removing the studies in the meta-analysis that deviated from HWE in the genotype distribution (Merza et al., 2009). The study results were not altered, indicating that the result of the meta-analysis were reliable. There was no evidence of publication bias in this meta-analysis (all $\mathrm{P}>0.05$ ).

The mechanism of how the VDR gene FokI polymorphism affects tuberculosis risk remains unclear. In vitro studies have shown that the FF genotype in the FokI polymorphism increases the transcription rate of the VDR protein, which displayed higher responses to vitamin D (Liu et al., 2004). In addition, haplotypes more accurately and consistently reflect associations between gene and disease than do individual polymorphisms (Reich et al., 2001). Evidence suggests that FokI, BsmI, ApaI, and TaqI polymorphisms synergistically increased tuberculosis risk (Bornman et al., 2004). Further studies examining gene-environment interactions should be taken into consideration in future analysis.

Some limitations of our meta-analysis should be addressed. First, our systematic review was based on unadjusted data, as the genotype information stratified for the main 
confounding variables was not available in the original papers and the confounding factors addressed in the different studies were variable. Second, studies included in the present metaanalysis were mainly conducted in Asian populations, and other ethnicities, including Caucasian, African, and others, should be investigated in future studies. Finally, only published English studies were included in this study, and thus publication and potential language biases may have occurred.

In conclusion, the FokI polymorphism in the VDR gene may be related to an increased risk of tuberculosis in Asians. Large-scale case-control and population-based association studies are necessary to validate the risk identified in the current meta-analysis and to investigate the potential gene-gene and gene-environment interactions in tuberculosis risk.

\section{Conflicts of interest}

The authors declare no conflict of interest.

\section{REFERENCES}

Alagarasu K, Selvaraj P, Swaminathan S, Narendran G, et al. (2009). 5' Regulatory and 3' untranslated region polymorphisms of vitamin D receptor gene in South Indian HIV and HIV-TB patients. J. Clin. Immunol. 29: 196-204.

Ates O, Dolek B, Dalyan L, Musellim B, et al. (2011). The association between BsmI variant of vitamin D receptor gene and susceptibility to tuberculosis. Mol. Biol. Rep. 38: 2633-2636.

Attia J, Thakkinstian A and D'Este C (2003). Meta-analyses of molecular association studies: methodologic lessons for genetic epidemiology. J. Clin. Epidemiol. 56: 297-303.

Babb C, van der Merwe L, Beyers N, Pheiffer C, et al. (2007). Vitamin D receptor gene polymorphisms and sputum conversion time in pulmonary tuberculosis patients. Tuberculosis 87: 295-302.

Bornman L, Campbell SJ, Fielding K, Bah B, et al. (2004). Vitamin D receptor polymorphisms and susceptibility to tuberculosis in West Africa: A case-control and family study. J. Infect. Dis. 190: 1631-1641.

Davies PD (2005). Risk factors for tuberculosis. Monaldi Arch. Chest Dis. 63: 37-46.

Haussler MR, Whitfield GK, Haussler CA, Hsieh JC, et al. (1998). The nuclear vitamin D receptor: biological and molecular regulatory properties revealed. J. Bone Miner. Res. 13: 325-349.

Hewison M (2008). Vitamin D and innate immunity. Curr. Opin. Investig. Drugs 9: 485-490.

Holick MF (2007). Vitamin D deficiency. N. Engl. J. Med. 357: 266-281.

Joshi L, Ponnana M, Penmetsa SR, Nallari P, et al. (2014). Serum vitamin D levels and VDR polymorphisms (BsmI and FokI) in patients and their household contacts susceptible to tuberculosis. Scand. J. Immunol. 79: 113-119.

Liu W, Cao WC, Zhang CY, Tian L, et al. (2004). VDR and NRAMP1 gene polymorphisms in susceptibility to pulmonary tuberculosis among the Chinese Han population: a case-control study. Int. J. Tuberc. Lung Dis. 8: 428-434.

Lombard Z, Dalton DL, Venter PA, Williams RC, et al. (2006). Association of HLA-DR, -DQ, and vitamin D receptor alleles and haplotypes with tuberculosis in the Venda of South Africa. Hum. Immunol. 67: 643-654.

Merza M, Farnia P, Anoosheh S, Varahram M, et al. (2009). The NRAMPI, VDR and TNF-alpha gene polymorphisms in Iranian tuberculosis patients: the study on host susceptibility. Braz. J. Infect. Dis. 13: 252-256.

Moore DD, Kato S, Xie W, Mangelsdorf DJ, et al. (2006). International Union of Pharmacology. LXII. The NR1H and NR1I receptors: constitutive androstane receptor, pregnene $\mathrm{X}$ receptor, farnesoid $\mathrm{X}$ receptor alpha, farnesoid $\mathrm{X}$ receptor beta, liver X receptor alpha, liver X receptor beta, and vitamin D receptor. Pharmacol. Rev. 58: 742-759.

Nnoaham KE and Clarke A (2008). Low serum vitamin D levels and tuberculosis: a systematic review and meta-analysis. Int. J. Epidemiol. 37: 113-119.

Olesen R, Wejse C, Velez DR, Bisseye C, et al. (2007). DC-SIGN (CD209), pentraxin 3 and vitamin D receptor gene variants associate with pulmonary tuberculosis risk in West Africans. Genes Immun. 8: 456-467.

Pittas AG, Lau J, Hu FB and Dawson-Hughes B (2007). The role of vitamin D and calcium in type 2 diabetes. A systematic review and meta-analysis. J. Clin. Endocrinol. Metab. 92: 2017-2029.

Rathored J, Sharma SK, Singh B, Banavaliker JN, et al. (2012). Risk and outcome of multidrug-resistant tuberculosis: vitamin D receptor polymorphisms and serum 25(OH)D. Int. J. Tuberc. Lung Dis. 16: 1522-1528.

Reich DE, Cargill M, Bolk S, Ireland J, et al. (2001). Linkage disequilibrium in the human genome. Nature 411: 199-204. 
Roth DE, Soto G, Arenas F, Bautista CT, et al. (2004). Association between vitamin D receptor gene polymorphisms and response to treatment of pulmonary tuberculosis. J. Infect. Dis. 190: 920-927.

Selvaraj P, Chandra G, Kurian SM, Reetha AM, et al. (2003). Association of vitamin D receptor gene variants of BsmI, ApaI and FokI polymorphisms with susceptibility or resistance to pulmonary tuberculosis. Curr. Sci. 84: 1564-1568.

Selvaraj P, Kurian SM, Chandra G, Reetha AM, et al. (2004). Vitamin D receptor gene variants of BsmI, ApaI, TaqI, and FokI polymorphisms in spinal tuberculosis. Clin. Genet. 65: 73-76.

Selvaraj P, Prabhu Anand S, Harishankar M and Alagarasu K (2009). Plasma 1,25 dihydroxy vitamin D3 level and expression of vitamin D receptor and cathelicidin in pulmonary tuberculosis. J. Clin. Immunol. 29: 470-478.

Singh A, Gaughan JP and Kashyap VK (2011). SLC11A1 and VDR gene variants and susceptibility to tuberculosis and disease progression in East India. Int. J. Tuberc. Lung Dis. 15: 1468-1474.

Søborg C, Andersen AB, Range N, Malenganisho W, et al. (2007). Influence of candidate susceptibility genes on tuberculosis in a high endemic region. Mol. Immunol. 44: 2213-2220.

Stead WW, Senner JW, Reddick WT and Lofgren JP (1990). Racial differences in susceptibility to infection by Mycobacterium tuberculosis. N. Engl. J. Med. 322: 422-427.

Taymans SE, Pack S, Pak E, Orban Z, et al. (1999). The human vitamin D receptor gene (VDR) is localized to region 12cen-q12 by fluorescent in situ hybridization and radiation hybrid mapping: genetic and physical VDR map. J. Bone Miner. Res. 14: 1163-1166.

Thye T, Vannberg FO, Wong SH, Owusu-Dabo E, et al. (2010). Genome-wide association analyses identifies a susceptibility locus for tuberculosis on chromosome 18q11.2. Nat. Genet. 42: 739-741.

Uitterlinden AG, Fang Y, Van Meurs JB, Pols HA, et al. (2004). Genetics and biology of vitamin D receptor polymorphisms. Gene 338: 143-156.

Valdivielso JM and Fernandez E (2006). Vitamin D receptor polymorphisms and diseases. Clin. Chim. Acta 371: 1-12.

Wilkinson RJ, Llewelyn M, Toossi Z, Patel P, et al. (2000). Influence of vitamin D deficiency and vitamin D receptor polymorphisms on tuberculosis among Gujarati Asians in west London: a case-control study. Lancet 355: 618-621.

Zembrzuski VM, Basta PC, Callegari-Jacques SM, Santos RV, et al. (2010). Cytokine genes are associated with tuberculin skin test response in a native Brazilian population. Tuberculosis 90: 44-49.

Zhang HQ, Deng A, Guo CF, Wang YX, et al. (2010). Association between FokI polymorphism in vitamin D receptor gene and susceptibility to spinal tuberculosis in Chinese Han population. Arch. Med. Res. 41: 46-49.

Zhong WG, Wang Y, Zhu H and Zhao X (2012). Meta analysis of angiotensin-converting enzyme I/D polymorphism as a risk factor for preeclampsia in Chinese women. Genet. Mol. Res. 11: 2268-2276.

Zhou LP, Luan H, Dong XH, Jin GJ, et al. (2011). Vascular endothelial growth factor gene polymorphisms and colorectal cancer risk: a meta-analysis. Genet. Mol. Res. 10: 3674-3688.

Zumla A, George A, Sharma V, Herbert N, et al. (2013). WHO's 2013 global report on tuberculosis: successes, threats, and opportunities. Lancet 382: 1765-1767. 